\title{
Gamification Elements and Their Potential Influence on Employee Motivation - A Literature Review of Models
}

\author{
Le Trung KIEN ${ }^{1}$ and Nguyen Danh NGUYEN ${ }^{2 *}$ \\ ${ }^{1}$ School of Economics and Management, Hanoi University of Science and Technology, Hanoi, Vietnam \\ ${ }^{2}$ School of Economics and Management, Hanoi University of Science and Technology, Hanoi, Vietnam \\ *Corresponding author: nguyen.nguyendanh@hust.edu.vn
}

\begin{abstract}
Gamification in reality so far has focused mainly on implementing a reward system through gaming elements such as score, badges, and leader boards. However, there are a lot more elements in game design than just a simple reward system, which need a model to compile them for design purposes. Therefore, this literature review aims at finding out what gamification elements could potentially influence employee motivation, and on what aspect, based on empirical studies on the relations between gamification and motivation. Important motivation theories are analysed to show on what aspect gamification can influence motivation, and a review of gamification models reveals gamification elements that are considered related to increasing motivation. The results indicate that there are many elements that could influence motivation in different ways, which includes Mechanics, Dynamics and Aesthetics.
\end{abstract}

\section{Research purpose:}

To understand how gamification designs can influence motivation for employees at work, and what implications it brings about.

\section{Research motivation:}

Gamification is an increasingly popular studied topic, yet a definite model for its impact on motivation is still under-researched. Hence, more insights of gamification definition as well as its impact on human motivation at work are needed to be unveiled.

Research design, approach and method:

Most studies on Google Scholar were conducted based on the keywords of gamification definitions, gamification elements, and motivation theories. Different papers were carefully selected based on their relevance and importance. Related concepts are compiled and analysed to identify important related concepts.

\section{Main findings:}

Gamified elements that could potentially influenced employee motivation the most can be grouped as Mechanics, Dynamics and Aesthetics. These gamified elements could increase employee motivation through the sense of self-determination, personal development, and competence.

\section{Practical/managerial implications:}

Businesses could use the model to better understand the approach of gamification design. Further research is also possible on the topic.

Keywords: gamification, motivation

\section{INTRODUCTION}

One of the lastest concepts in managing motivation is the application of gaming elements in non-game contexts, which is known as the gamification process (Deterding et al., 2013). Primary real-life examples of gamification can be shown by businesses promoting their loyalty programs to customers, or a hierarchical system of membership in air travel. Interestingly, most basic game elements can attract human psychology, especially motivation, such as accomplishment, improvement, competition, ownership and socialisation. In reality, these elements can be adopted in fields outside the game box, which takes study of gamification to be a freshly researched area (Deterding et al., 2011). In fact, researches on the adaptation of gamification are gaining increasing popularity, which foresees a potential future of widespread usage in organisations and 
businesses. Therefore, it is important that a systematic approach to the process of gamification should be applied in different contexts, particularly in businesses.

\section{Gamification elements as a catalyst to enhance employee's motivation}

Generally, the element of psychology must be the main focus when dealing with motivation. Mental arousals at work, such as feelings of enjoyment, dedication, immersion, challenge, etc., are also the usual observed results when playing games (Reeves \& Reed, 2009). This is explained that individual motivations reflected from games are similar to real-life drives for behaviour. Hence, the appeal of games comes from the attention attraction, engagement induce, and interest satisfaction (Reeves \& Reed, 2009). Game elements, when adopted in organisations, could be highly beneficial for employee motivation. In gamification research, the main focus lies on work processes and how to improve their presentation, rather than studying different aspects of an organisation (Aziz, Mushtaq \& Anwar, 2017; Zichermann \& Cunningham, 2011).

In gamification studies, basic game elements can include points, badges, rewards, missions, challenges, and competition. The gamification process is the use of these elements and the basis of psychological theories to engage and motivate employees. In theory, gamification can provide employees with validation and self-fulfilment with their completed tasks, which can increase motivation at work. According to the theory of self-determination, it is suggested that when human psychological needs such as validation, skills progressing, or socialisation are fulfilled, self-operating behaviour can occur and increase motivation. Furthermore, with gamification, routine activities can become more interesting, while complex tasks can be simplified with clear objectives and instructions. For instance, employees can unlock special privileges at work such as access to social media or additional day-offs, as achievable abilities based on their work performance. Employees may also observe their work status and progress through task trackers or leaderboards, to see how well they need to perform in order to attain certain positions. This means that rewards, progression and status through gamification can be a means of satisfying individual psychological needs at work (Murawski, 2020).

This paper proposes that gamification could become a useful tool for improving motivation issues. In the age where competitiveness, creativity and technology are the prime of success, conventional managing strategies are becoming obsolete. Especially, with the upcoming young generation who are more familiar with fast-paced gratification and creative thinking, traditional tasks and work setting are less becoming appealing. Thus, gamification, which is a fresh change of managing format, could be the right tool managers are looking for.

\section{RESEARCH QUESTIONS}

As a result of the lack of designated framework and possible consequences from literature findings, there is an exploratory nature in the research of gamification. Thus, gamification and its impact on motivation at workplace is consequently an area that needs stronger theoretical foundation. The three research questions are:

1. What are the most important gamification elements used in research models and frameworks for businesses?

2. What aspects of motivation can be affected from gamification elements in business environment?

3. What framework can managers use to build and apply gamification for motivation purposes at work?

Previous work of theoretical literature and empirical evidence should provide an adequate basis to answer three research questions. For better understanding of the mentioned notions, the two questions provide an orientation to which gamification will be observed in relation to the concepts of motivation in organisational settings.

\section{METHODOLOGY}

Relevant literature review was conducted through searches on Google Scholar, Scopus and Web of Knowledge. Literature considered relevant are selected based on:

- Definitions, purposes and frameworks of gamification; game elements - especially those that could induce engagement and motivation.

- Popular theories of motivation; definitions of different types of motivation, and how to influence intrinsic motivation at work

- Models/ frameworks that describes how gamification can impact user engagement, motivation and performance in businesses.

- Models/ frameworks that explains how gamification can impact employees' intrinsic and extrinsic motivation in businesses.

The literature review covers a large number of materials in the field of study. The selected data include research papers in peer-reviewed journals and models from businesses or expert researchers. This includes books, empirical studies, literature review and secondary analyses. The literature only counts publications written in English. The research is not filtered by year.

Most chosen literature about gamification are more recent ones since these are considered more reliable. Papers on motivation its psychological theories, however, are chosen based on their popularity and importance to general research on the topic. After that, the most popular or common elements of gamification from gamification models are thoroughly selected and combined with closely related motivation aspects to find 
which elements are the most important, in order to analyse their impacts on relevant motivation factors. In summary, Table 1 illustrates criteria for identifying most relevant materials for the research.

Table 1: Inclusion and exclusion criteria for literature review

\begin{tabular}{|c|c|c|}
\hline Criteria & Inclusion & Exclusion \\
\hline $\begin{array}{l}\text { Results of } \\
\text { literature } \\
\text { search }\end{array}$ & $\begin{array}{l}\text { findings with relevant } \\
\text { keywords: } \\
\text { gamify, gamified, motivation }\end{array}$ & Other \\
\hline Literature & $\begin{array}{l}\text { Peer-reviewed journals, books, } \\
\text { online sources by experts that } \\
\text { contains models or frameworks } \\
\text { of gamification elements }\end{array}$ & Other \\
\hline Study & $\begin{array}{l}\text { Empirical study, secondary } \\
\text { analysis, literature review }\end{array}$ & Other \\
\hline Language & English & Other \\
\hline Context & $\begin{array}{l}\text { Business setting, employee } \\
\text { influence }\end{array}$ & Other \\
\hline
\end{tabular}

\section{RESULTS}

The initial search reveals 336 titles relevant to the research. A total of 114 paper were excluded because research context was not in business setting (education, health, etc.), or no clear model/framework was found. A final number of 22 studies and models were classified into the literature review, as shown in Fig 1.

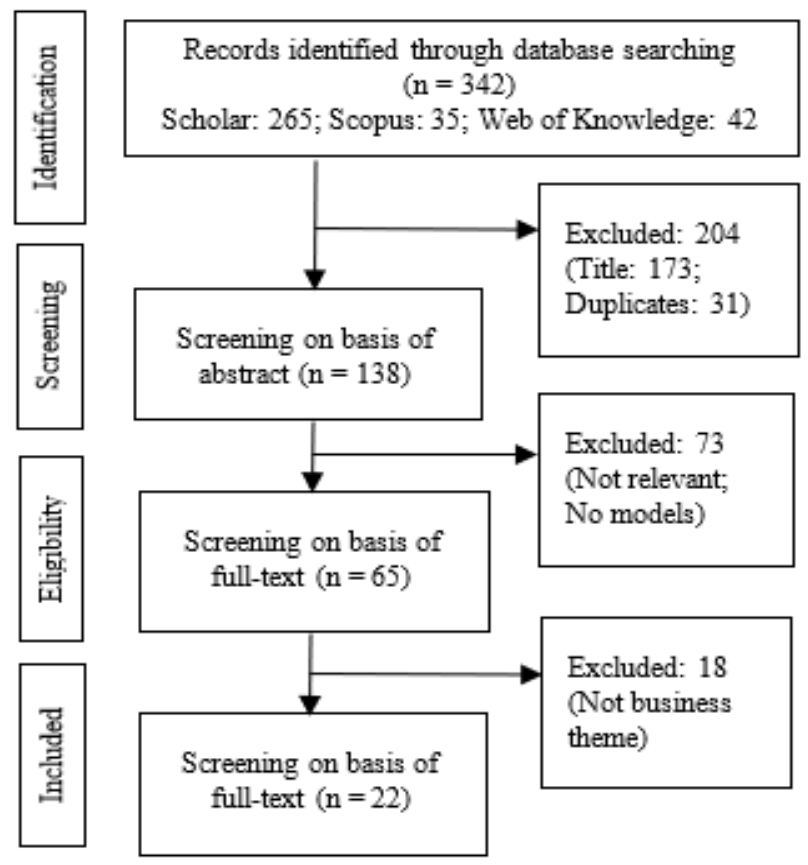

Fig 1: Process diagram of literature review

\subsection{Gamification studies in businesses}

To put it simply, gamification is the process crafting fun and exciting factors of games and into non-game contexts to engage an audience and/or to change behaviours. The focus of gamification is the psychological arousal, mostly human motivation and engagement, in order to attract attention and stimulate a pattern of behaviour. This is different from game design, where the goal is not about winning the game in a certain context, but to finish certain tasks or to behave in certain ways. This means that in game design, the developer starts with an idea; while in gamification design, the developer begins with an objective, or as put by Yu-kai Chou (2019), "core drives".

Among studies of gamification at work, there is a heavy focus on employee motivation and engagement to improve performance. Gamification can be a powerful tool to motivate and engage employees at work (Dubey et al., 2016; Jabagi et al., 2019; Ruhi, 2015; Liu et al., 2018). Di Tomasso (2011) shows a framework based on self-determination theory of motivation, which involves discovering reasons for gamification, identifying player types, setting up goals, describing skills, finding out areas of interest and completing the process. Landers and Armstrong (2017) suggest 4 employee variables to establish this framework. One major aspect is Employee Motivation is one of the most important factors contributing to how productively one performs (Junior, Santos, Carvalho, Gabriele de Paula Silva \& Silva, 2013). Next, Employee Engagement defines the level of investment an employee has, due to the decrease in tedium of tasks in a gamified environment (Suh et al., 2017). This is followed by Employee Loyalty and Employee Retention (Basten, 2017) which are proved surprisingly successful in gamification at work. These variables influence upon each other and have a mutual relationship with gamification.

There is also a perception to link gamification with younger generation, especially Generation Y (born 1986-1995) and Generation Z (born after 1996) because these generations are exposed to the usage of technology since they were born (Jacobs, 2016; Jain \& Dutta, 2018). Researchers argue that technology brings about a faster pace of life, which in turn promoted the behaviour of quick rewards and incentives through at workplace, with elements relevant to gamification such as achievements (Werbach, Hunter, 2012). Some organisation caught up with this idea and transformed itself with gamification techniques in order to increase motivation among employees of younger generation, because they are either early in their career (Generation $\mathrm{Z}$ ), or close to a full-time vacancy (Generation Y) (Vinichenko et al., 2016).

\subsection{Most noticeable gamification elements from literature review}

Multiple different gamification models were revised and analysed to pick out the most common gamification elements (see Table 2). Adapted from the MDE Framework, all gamification elements chosen are divided into three main categories: Mechanics, Dynamics and Aesthetics. (Robson, Plangger, Kietzmann, McCarthy \& Pitt, 2015; Basten, 2017; Kusuma, Wigati, Utomo \& Putera Suryapranata, 2018). 
Table 2: Literature details

\begin{tabular}{|c|c|c|c|}
\hline Author(s) & Year & Research Type & Game elements \\
\hline Adams \& Makramalla & 2015 & Solution proposal & $\begin{array}{l}\text { Points, badges, leaderboard, } \\
\text { avatar, story, shared purpose/goal }\end{array}$ \\
\hline Basten & 2017 & Proof of concept & Mechanics \& Dynamics \\
\hline Bhattacharyya et al. & 2018 & Evaluation research & Play and choice, exposition, information, engagement, reflection \\
\hline Dalmina et al. & 2018 & Review & $\begin{array}{l}\text { Mastering skills. challenge, guidelines, engagement, improving } \\
\text { learning, socialization }\end{array}$ \\
\hline Di Tommaso & 2011 & Proof of concept & Fun, competence, autonomy, relatedness \\
\hline Escribano \& Gali & 2016 & Proof of concept & $\begin{array}{l}\text { Spontaneous situations, challenging problems, top experiences, } \\
\text { exciting experiences, resources }\end{array}$ \\
\hline Hassan & 2017 & Solution proposal & $\begin{array}{l}\text { Extrinsic rewards, intrinsic rewards, civic engagement } \\
\text { prerequisites }\end{array}$ \\
\hline Hoglund & 2014 & Solution proposal & Dynamics, mechanics, components \\
\hline King & 2013 & Proof of concept & $\begin{array}{l}\text { Accomplishment, ownership, meaning, scarcity, empowerment, } \\
\text { social influence, avoidance, unpredictability }\end{array}$ \\
\hline Kumar & 2013 & Solution proposal & Points, badges, achievements, leaderboard \\
\hline Landers \& Armstrong & 2017 & Evaluation research & Instructions, points, rewards \\
\hline Landers et al. & 2015 & Evaluation research & Leaderboards, goals \\
\hline Liu et al. & 2018 & Evaluation research & Points, badges, achievements, leaderboard \\
\hline Marczewski & 2015 & Proof of concept & $\begin{array}{l}\text { Relatedness, autonomy, mastery, purpose \& meaning, change, } \\
\text { rewards }\end{array}$ \\
\hline Mitchell et al. & 2020 & Evaluation research & Relatedness, autonomy, competency \\
\hline Quantic Foundry & 2021 & Solution proposal & $\begin{array}{l}\text { Destruction, competition, challenge, completion, fantasy, } \\
\text { design, excitement, community, strategy, power, story, discovery }\end{array}$ \\
\hline Richter & 2015 & Review & $\begin{array}{l}\text { Visual/sound effects, progress bar, points, challenges/quests, } \\
\text { badges, leaderboard, achievements, avatar }\end{array}$ \\
\hline Suh \& Wagner & 2017 & Evaluation research & $\begin{array}{l}\text { Rewardability, competition, visibility Of achievements, } \\
\text { quality/quantity of knowledge contribution }\end{array}$ \\
\hline Suh et al. & 2017 & Evaluation research & $\begin{array}{l}\text { Reward, status, competition, self-expression, flow/aesthetic } \\
\text { experience }\end{array}$ \\
\hline Werbach \& Hunter & 2014 & Solution proposal & Components, mechanisms, dynamics \\
\hline Xi \& Hamari & 2019 & Evaluation research & Immersion, achievement, social \\
\hline Yu-kai Chou & 2019 & Solution proposal & $\begin{array}{l}\text { Meaning, accomplishment, empowerment, ownership, social } \\
\text { influence, scarcity, avoidance, unpredictability }\end{array}$ \\
\hline
\end{tabular}

\section{Mechanics}

Mechanics are basic game elements that constitute a gamification process. This can include:

- Points: Points are the most basic unit of measurement that quantifies a user's activity and progression throughout the gaming experience. Points can also be used as a currency of exchange or means of unlock. Different types of points are designed strategically in game mechanics in order to reflect different measurement to create a diverse and creative experience: Absolute status points measure total amount of progression (usually known as Experience points), Marginal status points measure progression in a period of time, which can be reset after the period ended (usually used as scores in challenges or competition), One-way status points are points that will only go up (could be used to indicate the development of a character, such as levels or stats), and Two-way status points that could go down in certain situations - usually in failure of certain tasks. Points are the most important indicator of a user's performance, and are almost always visible for constant feedback and immediate evaluation.

- Feedback: Feedback is measurements based on points to let users know "where they stand in relation to hitting their goals". This helps users with understanding the game mechanics and pathway and show them what they can expect in their continued progress. Notifications and points are the most basic form of feedback - a simple "Great Job!" popping up is very common in various gaming environment. It is important that feedback in gamification is instant to make players continuously aware that they are working on the right path and feel highly relevant to their progression. Constant feedback is also much more accurate and reliable than traditional appraisal methods that only take place procedurally once or twice per year.

- Leaderboard, Ranking \& High score: A leaderboard is a list that displays the names, points and positions of individuals or teams with the most points. Leaderboards are a simple visual representation of status and 
progression of all users, which can be used for comparison. Leaderboards boost competition and hence can induce either satisfaction or frustration.

- Achievements: Achievements and badges are virtual symbols used as a form of feedback and reward to signify certain accomplishments. Achievements are visual display indicating the user's capability measured in the gaming environment. Achievements and badges could increase performance expectations, user self-efficacy, goal commitment; and also induce satisfaction and support social proof.

- Goals \& Objectives: Goals and objectives are requirements to win. Clear and SMART goals are important practice that is well known among managers, and gamification is no exception on that basis. Of course, goals in games can be modified with a different theme to illude and transform boring KPI into more "friendly" concepts such as gold coins, candies, power levels, etc.

- Tutorial: Tutorial is an interactive message that present instructions and greetings to welcome users to the gaming experience. Tutorial is a short and simple training session for those who experience the game the first time, and can also be used to showcase what the game is about and create an emotional bond with the users. Tutorial is an important first-impression.

- RNG: RNG is short for Random Number Generator, or simply put, the element of "luck". RNG is widely used to create an unpredictable outcome for certain activities, in order to keep users engaged with a game because of the sense of mystery or surprise, with a hint of curiosity. This mechanic is extremely powerful, which has shown in many controversies such as Electronic Arts's law suit on over-abundance usage of loot boxes for cash grab, or Tencent's notoriety of money extortion from players on chance-based game mechanics. Being highly addictive, similar to gambling, RNG must be used under utmost caution for potential negative causality.

\section{Dynamics}

Dynamics are the relationships between designed mechanics and the basic experience that users can come across through their interaction with the game mechanics, or to put it simply, how the gamification is meant to be played. Dynamics can include:

- Rules: Rules are the basis of any games. Rules are restrictions and requirements on which players have to follow to complete the game. Rules create a sense of equality, as everyone is affected by them in the game.

- Rewards: Rewards are tangible or extrinsic benefits from an external source, which could be seen, used, spent, or sometimes touched by users that earned them. Rewards are commonly used for behaviour conditioning and user motivation, which is useful for quick motivation in short-term. Rewards should be carefully considered, however, because they are not necessarily the most effective and sustainable form of motivation in the long run.

- Unlockables: Unlockables are special or rare content of the game that can only be acquired by completing certain tasks and not through standard gameplay. Unlockables are not mandatory, and they exist in the spirit of "just for fun". This is important to make a game truly fun, because when everything exist to serve a specific purpose that is in line with the ultimate goal, the game gets very tense and serious. However, if something exists just for the sake of "having fun", it can serve as a "relax valve" that reduces tension and focus in the game, which is similar to taking a break and having leisure time. Unlockables can also be used for collecting purposes, for those who are "completionists" that want to finish the game as thoroughly as possible.

- Missions \& Tasks: Also known as "Quests", missions and tasks are the set of rules, information and behaviour required to complete the game and win rewards. Missions and tasks can also be accompanied with challenges to vary the range of difficulty with a freedom of choice - users can choose to complete challenges to earn even more rewards, which is not compulsory. Different types of missions can mix together for a combination of a diverse experience, including main missions, side missions, achievement tasks, mini-quests, etc.

- Teamwork \& Collaboration: The connection with peers and colleagues can be challenge in a fun environment of gaming. Game activities can be completed in teams which will require teamwork and collaboration skills. Teamwork can also include knowledge sharing and peer assistance which is also importance for a healthy work environment.

- Competition \& Conflict: Competition is necessary to encourage users to put their highest efforts, because winners must have the best performance. A healthy competition is a great boost of motivation and productivity.

- Performance graph \& Progression system: Progression system is important in any game because it travels through the game with the player. A good progression system keeps the flow going and hence enhance engagement in gameplay. Performance graph is the indicator of progress, usually in forms of a progress bar. Performance graph is a graphical element that describes user's performance and task completion rate. Performance graph can urge and tease users to complete their task, which is useful to make employees go one step further in their work. However, progression can also be an obstacle which users have to overcome. For example: in some gameplay design, player will not pass certain section because of ability limit or rank limit.

- Flow: Flow theory is a popular concept in gaming and gamification design. The flow state is the ideal status of a player where he/she is most focus and produces the highest productivity (Shernoff, Csikszentmihalyi, 
Shneider \& Shernoff, 2003; Perttula, Kiili, Lindstedt \& Tuomi, 2017). This happens when skills and difficulty increase proportionally, which means that when the task is too hard or too easy, the player could get anxious or bord, resulting in dissatisfaction in gaming experience. Keeping the flow of the game depends on the identification of skills required, with a set of tangible goals and manageable rules. Flow state can induce great motivation since it promotes feelings of focus, mastery, awareness, productiveness, and enjoyment in task.

\section{Aesthetics}

Aesthetics are described as how users' emotions are affected through the gamification tool. Aesthetics can include:

- Visual \& Sound effects: These are sensory cues that trigger when a certain scenario occurs. When a player level up, for example, fireworks and music could be played in order to celebrate the occasion. Carefully designed visual and sound effects can be powerful tools to promote condition learning and motivate behaviour.

- Avatar: An avatar is an icon or figure that shows an in-game representation of a user. Avatars can be chosen or personalized, which gives users the sense of ownership and control over their "character", creating an emotional bond between them and their digital persona. Avatar is a fun image of oneself which also reflects an ego or alter-ego of a person, and possibly boosts the user's confidence. Avatar also holds a feeling of control, which promotes the biological need for existence and reduce the feeling of anxiety and insecurity. An avatar can also make the application feel close and personal, triggering a sense of possession.

- Narrative: Narrative depicts a clear purpose which a user can embrace and "join the cause". If a user can see an understand a purpose, they will see something that they can dedicate their time and effort to. A powerful narrative can do just that and possibly more. A narrative showcases information for players in forms of stories and events in chronological order, so that they can take actions accordingly. A narrative is not just about a story and its meaning: it is about the way the story is told the way story events are displayed is an art that lies in details, not a generic theme. A narrative can include an epic meaning that urge people to become a part of something greater than themselves, which sometimes can motivate people to an unimaginable degree.

- UX-UI: UX (User Experience) \& UI (User Interface) are similar to visual and sound effects, but it serves more as a tool for user to easily familiarize with the gamification experience. Smart UX-UI design can take a lot of time, but very necessary because good design can greatly reduce user frustration and annoyance when playing, while promoting certain behaviour to repeat if beneficial. In game design, UX-UI is sometimes referred to as "Quality of life" design.

- Style \& themes: Styles and themes could be anything that could either be closely related to the aim of the project, or something entirely different. Styles and themes are the bridge that connects the narrative with the gameplay, which shows a clear subject to engage users in a creative journey. Consistency is important in this sense, that permeate the whole story and create an immersive experience.

- Easter eggs: Just like its name, an easter egg is a vivid, sudden and unpredictable form of "reward". Easter eggs are not obtainable through traditional gameplay; rather, it is like a hidden "joke" or reference that is usually evading eyesight. Most players will never encounter or notice an easter egg, and it only becomes apparent once they are known. Easter eggs are slightly similar to a special type of collectibles, which exists just for the sake of fun, which adds an extra level of satisfaction that can improve user engagement.

\section{DISCUSSION}

\subsection{Gamification and the psychology of motivation}

All motivation theories have common grounds with the design of games and gamification tools, which trigger human's subconscious drives to action and behavioural change. Motivation (and engagement) theories are studied heavily in game design. Gamification, therefore, is closely related to the issue by similar logic. Based on these foundations, researchers have put many psychological theories of motivation to explain how Gamification motivates employees (Dalmina, Barbosa \& Vianna, 2018).

In order to understand how gamification impact on performance and productivity in an organisation, it is usually related with specific variables of employee psychology and intrinsic behaviour. Intrinsic motivation is believed to truly motivate employees at workplace, rather than extrinsic motivation (Herzberg, 2003). Self-determination theory (Deci \& Ryan, 2012) claimed that people have three basic psychological needs, which are autonomy, competence and relatedness. These are the three factors that encourage human to move towards growth, which can be found in gaming effects (Perryer, Celestine, Scott-Ladd \& Leighton, 2016; Xi \& Hamari, 2019). The act of satisfying these needs can drive people to participate in a gamified experience (Sailer, Hense, Mayr \& Mandl, 2017; Mitchell, Schuster \& Jin, 2020). Matsumoto (2016) added the importance of self-determination theory in this sense, which also affects intrinsic motivation. The needs of exposition (narratives and meanings), information (knowing and understanding) and reflection (feedback, self-reflection and self-fulfilment) are also suggested for Gen Y users of gamification (Bhattacharyya, Jena \& Pradhan, 2018).

Moreover, Locke's Goal Setting theory (Locke \& Latham, 1990) emphasizes the impacts of setting goals on one's future job performance, which suggests that people with specific and challenging goals perform better and more determined than people who set approachable goals - which is of course one of the main 
visible elements of gamification (Marczewski, 2012)

Another famous motivation theory is Vroom's Theory of Expectancy (Lee, 2007), which explains that person's performance is based on the outcomes they expect, and motivation originates from their voluntary behaviour. Specifically, motivation is determined by considering three factors: Expectancy - belief that they will succeed with efforts; Instruments -concern about the connection between performance and goal; Valence - perception of the value of the result. In the case of gamification, outcomes can be predicted through illustrations that are shown clearly to users, which could induce motivation according to Vroom (Yu-kai Chou, 2019).

Another relevant theory is the Hawthorne Effect (Adair, 1984), which refers to one's higher work performance under others' observation. Researchers found out that one's environment and people around them have a great impact on their productivity; employees are more focused on their jobs and as a result achieve higher performance. The Hawthorne Effect suggests that motivation can be obtained when employees got the special attention of being valued or being given some autonomy, regardless of their preferences, work practices, habits, etc. This is of course a possible result in the gamification process, where both autonomy and observation are linked in the game elements (Nacke \& Deterding, 2017; Yu-kai Chou, 2019).

Further, Skinner's Operant Conditioning Theory (Skinner, 1963) states that one behaves according to the consequences of their work, whether it is Positive reinforcements (praises, good marks, money, promotion), Negative reinforcement (eliminating unpleasant states) and Punishment (undesired reinforcements or reinforce undesired behaviours). Skinner claimed that the best way to understand and access motivation is to analyse the cause of an action and its consequence. These reinforcements are the main approach that game design uses to engage users and possibly "train" their behaviour. Accordingly, game elements in gamification fulfil the above-mentioned perspectives in one way or another. For example: points serve as an instant positive reinforcement (feedback) and reward; badges serve as proof of success, status, goal setting, or competence; leaderboards can show achievement or provoke competition (Nacke \& Deterding, 2017; Yu-kai Chou, 2019).

It could also be argued that, since game elements reflect or simulate elements of life (sense of ownership, achievement, relaxation, development, status, or even survival), gamification can potentially virtually fulfil human's most basic needs, which drives motivation. Interestingly, a higher and more poetic need was also raised, which is the need of an Aesthetic Experience, which can contribute to keep the players participating in the gamified experience (Suh, Suh, Cheung, Ahuja, Wagner \& Wagner, 2017).
5.2. A proposed framework of the relationship between gamification elements and motivation factors

Along with gamification elements, appropriate motivation factors relevant are also from motivation theories to show the effects of gamification elements on motivation (see Fig 2). As identified in the literature review, three main categories of motivation factors are summarised in a potential framework: Self-determination, Personal development and Competence (see Fig 3).

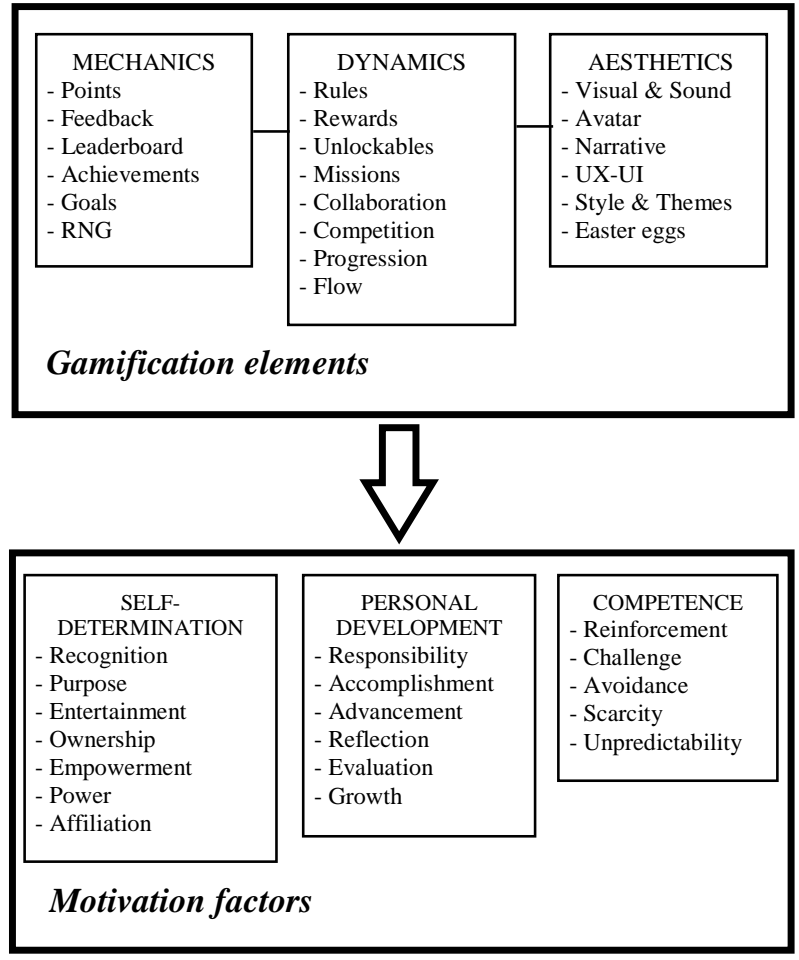

Fig 3: Gamification elements and motivation factors framework

In this section, motivation factors in the proposed framework are described below, along with their sub-factors.

\section{Self-determination}

Self-determination is how a person defines oneself. Understanding and acquiring one's own traits, capabilities, status, relationship and interest is among the most important motivation factor in many theories. Self-determination sub-factors derive from gamification models include:

- Recognition: Recognition is extremely important motivation factor at workplace, which is easily done with gamification. By quantifying and visualizing employees' efforts, gamification makes it easy for managers and colleagues to see who is working harder. Recognition also sends a message about what success is about, which is an effective tool for both personal reward and organizational desired culture reinforcement. 
- Purpose: motivation is individual and situational, which means the aim for motivation is subjective. However, a purpose sets an ideal and desired status that can turn subjective aims aligning with objective goals or common goals. A purpose is not just a simple goal; it is to contribute to something greater than oneself, and therefore is the highest level of motivation. A gamification environment can assist with visualizing a virtual purpose that can drive users to be highly motivated.

- Entertainment: This sub-factor can stand alone as its own motivation factor, as one of the main goals of gamification is to create a fun experience. However, entertainment is a sub-category of self-determination, as satisfying mental crave for eudaimonia is a part of human psychological needs, and gamification offer just that in a virtual manner. Therefore, it is clear that gamification can provide entertainment as a means of motivating users.

- Ownership: Ownership is a feeling of possession, which is a part of human's need for autonomy. The state of psychology of ownership is affective because it creates an emotional connection toward what one owns, which is very important for motivation at work. In gamification, ownership is ubiquitous, from a personalized avatar, to a rare collectible that one receives. If the sense of ownership is high during the gamified experience, users are more attached to it and are more motivated to complete given tasks.

- Empowerment: Empowerment enables better performance through the sense of autonomy and self-management. Gamification create an environment where the players control their d estinies, and hence, give them a sense of empowerment.

- Power: Power motivates people through the desire to make an impact on other, to be strong and influential. This is a very basic instinctive needs as everyday life is usually a competition for all living beings. It is very natural to be motivated when one has a sense of power. Gamification tools can stimulate the feeling of power through the virtual character, badges, leaderboard, or rewards. The attempt to make the character more powerful could even become too motivative - also known as addictive.

- Affiliation: The desire to experience and maintain close relationships with other people is considered one of human's basic needs. Affiliation motives are perceived as a strong motivating force, directing behaviour and decision making. The need for affiliation can also create a sense of conformity, which can psychologically unify a group to a certain behaviour. Gamification could serve as a network in which users are connected and interactive, and hence provide methods of interactions such as communicating (chatting, commenting, ...), trading/ sending gifts, teamworking, competing, etc. Motivation for affiliation is visibly effective but also subtly dangerous, as virtual interactions could overwhelm physical - or real life interactions.

\section{Personal development}

Personal development is one of the higher needs in Maslow's hierarchy, which is also mentioned as the true intrinsic motivation factor in Herzberg's theory. Personal development sub-factors in gamification models are summarized as:

- Responsibility: People are motivated when their responsibilities are meaningful and relevant to their abilities and values. Responsibilities could be developing skills, helping other, or building a strong group. Employee responsibility can be stimulated through gamification elements such as feedback, character development, goals \& objectives, missions \& tasks, teamwork \& collaboration, performance graph \& progression system, and autonomy and individualization. Gamification can bring about visual representation of one's status and progression as a subtle reminder for them to do their work. Hence, they could feel responsible and become more motivated to complete tasks.

- Accomplishment: Accomplishment motivation is the need for excellence and great achievement, regardless of what rewards may follow. Accomplishment offers a sense of noticeable success or betterment, and with that, also a fear of failure. This means that people will be motivated to work and to finish the task which they feel they are able to accomplish. Accomplishing a difficult task is also very rewarding psychologically. Gamification environment offers clear representation of accomplishment in forms of points, badges, leaderboard, progression bar, rewards, etc., which can motivate users to keep coming back for more.

- Advancement: Career path and opportunities for promotion can motivate stronger job performance. Gamification can tie with career advancement as a real tangible reward in order to have a true reward rather than just having fun. The spiral of advancement, motivation, satisfaction and feedback is pivotal to employee performance.

- Reflection: Reflection refers to the way people think and feel about their experiences and formulate a response for them. Self-reflection is related to the sense of self-awareness and self-respect, which are higher motivation factors. Reflection can occur via gamification processes from simple points and badges, to competition and leaderboard.

- Evaluation: Similar to reflection, evaluation determines one's values and efforts through accomplishments. Evaluation in businesses is usually an extremely tricky task because appraisal systems are usually unreliable and ineffective. However, Gamification provide constant feedbacks, and numerical and visual evaluation in forms of points, ranking, badges, etc. Evaluation, along with recognition and 
feedback, is very important to make employees feel that they are acknowledged and valued for their work, and therefore is an important motivation factor at work.

- Growth: The sense of becoming better is always a good motivation factor. In gamification, growth is not about simply about progression or accomplishment; rather, it is about learning, training, or even changing oneself. Growth shows the fruits of long-term efforts or the "grind" - and the difference between. It is the journey that makes growth so motivating to look back, and look forward as well. Gamification is a good tool for training and learning, with clear progression along the way to push the users forward.

\section{Competence}

Competence is the ability of mastery and being effective/proficient in dealing with environment. When people feel that they have the skills needed to succeed, they will be more motivated to complete a task or work towards their goal. Competence sub-factors in a gamified environment can include:

- Reinforcement: reinforcement is an essential tool in behavioural shaping, according to Skinner's operant conditioning theory. Gamification produces reinforcement through instant feedbacks and rewards, which created learned behaviours through the process. This is also the basis of game design in general, forming rewards and notifications with happy music and bright colours to celebrate success, and displaying dark colours and silly/slow/sad music to signal failure. Reinforcement is key to systematic motivation and must be available in any gamification environment.

- Challenge: Challenges can be a great motivator, as studied in Herzberg's two-factor theories and flow theory, because they can keep employee engaged and interested in their tasks. Overcoming a good challenge can also be a reward itself, as it shows one's capability and skills. With gamification, a challenge can also be rewarded with badges that can be displayed to show others of one's accomplishment. Gamification design can dig deep in creating challenges to strip off boredom from mundane work and motivate employees.

- Avoidance: Avoidance is an interesting concept of gamification motivation. Similar to negative reinforcement, avoidance motivates people to behave "correctly" in order to avert from undesired state, such as losing something valuable (points, progress, highscore, etc.). The fear of losing progress or a golden opportunity is a great motivation for users to act immediately. This is very clearly analysed in Yu-kai Chou's Octalysis model, and is a clear proof of how gamification can motivate.

- Scarcity: Scarcity is what make something valuable, and hence, can motivate people to find or maintain it. Yu-kai Chou explains that it is natural to want things one cannot have, which is completely "unintuitive, irrational and emotionally difficult to utilise".
Gamification design can sometimes put in limitations or exclusivity such as countdown timer or special rewards to trigger the sense of wanting to act fast - quite similar to the effect of avoidance.

- Unpredictability: Anyone can enjoy the element of surprise or chance. The unknown can trigger immediate attention, and luck-based special reward can help increase engagement even further. Human are curious creature, and hence when new information arises, people are intrigued to explore and discover it. RNG or gambling are very simple but grossly effective tools that can hook users to spend a lot of time and efforts on it, because when the odds are uncertain, people are more engaged.

To conclude, gamification elements' relationship with motivation can be explained through motivation theories and psychological needs. In reality, gamification tools have shown positive results for motivation in education, and some cases in management as well.

\section{CONCLUSION}

Creating a gamified experience are tightly relevant to creating a gaming experience; yet, it is important to pick out appropriate elements for the most effective results, because the purpose and process of gamification are quite different from games' (Deterding, Dixon, Khaled \& Nacke, 2011). Gamification is not for pure entertainment - it serves as a means of enhancing engagement and motivation. In reality, playing games does not limit to any demographics: any one can have the capacity to enjoy being a "gamer" if there are reasons and incentives to do so. As a result, gamification could be the key to future management. However, the element of individual differences is still very important in the design of gamification. Although anyone can participate in games or gamification, perceived benefits still vary with demographic differences (Koivisto \& Hamari, 2014) or play styles (Lopez \& Tucker, 2019). Therefore, while gamification can serve multiple purposes because of its effects on motivation in an organisation, it needs to be designed with nuance and caution.

\section{REFERENCES}

[1] Adair, J. G. (1984). "The Hawthorne effect: A reconsideration of the methodological artifact". Journal of Applied Psychology, 69(2), 334-345.

[2] Adams, M. \& Makramalla, M. (2015). "Cybersecurity skills training: An attacker-centric gamified" approach. Technology Innovation Management Review, 5(1): 5-14.

[3] Armstrong, M. B., \& Landers, R. N. (2018). "Gamification of employee training and development: Gamification of employee training". International Journal of Training and Development, 22(2), 162-169

[4] Aziz, A., Mustaq, A. \& Anwar, M. (2017) "Usage of Gamification in Enterprise: A review". 249-252. 
10.1109/C-CODE.2017.7918937.

[5] Basten, D. (2017). Gamification. IEEE Software, 34(5), 76-81.

[6] Bhattacharyya, P., Jena, L. K., \& Pradhan, S. (2018). "Does "meaningful gamification" address gen Y needs? exploring its influence on creating meaningful engagement for gen Y workers". Human Resource Management International Digest, 26(1), 11-13.

[7] Dalmina, L., Barbosa, J.L.V. \& Vianna, H.D. (2018). "A systematic mapping study of gamification models oriented to motivational characteristics". Behaviour \& Information Technology, 38(11): 1167-1184.

[8] Deci, E. L., \& Ryan, R. M. (2012). "Self-determination theory". In P. A. M. Van Lange, A. W. Kruglanski, \& E. T. Higgins (Eds.), Handbook of theories of social psychology, 416-436.

[9] Deterding, S., Björk, S., Nacke, L., Dixon, D., \& Lawley, E. (2013). Designing gamification: Creating gameful and playful experiences. Paper presented at the 3263-3266.

[10] Deterding, S., Dixon, D., Khaled, R., \& Nacke, L. (2011). From game design elements to gamefulness: Defining gamification. Proceedings of the 15th International Academic MindTrek Conference: Envisioning Future Media Environments, 9-25.

[11] DiTommaso, D. (2011) "Beyond gamification: Architecting engagement through game design thinking" [online]. Retrieved from: http://www.slideshare.net/ditommaso/beyond-gam ification-architectingengagementthrough-game-design-thinking

[12] Dubey, M., Vishal, C. and Patil, D.Y. (2016). “A conceptual study of selected companies using gamification for employee training \& development as engagement approach". Amity Global HRM Review, 6: 73-80.

[13] Escribano, F. \& Gali, J.M. (2016). "Gamification Model Canvas Framework. Evolution.” [online]. Retrieved from: https://gecon.es/gamification-model-canvas-frame work-evolution-2/

[14] Hassan, L. (2017). "Governments Should Play Games: Towards a Framework for the Gamification of Civic Engagement Platforms". Simulation \& Gaming, 48(2):249-267.

[15] Herzberg, F. (2003). "One more time: How do you motivate employees?". Harvard Business Review, 81(1): 87.

[16] Hoglund, P. (2014). Gamification in training: engagement and motivation. Thesis at Hanken School of Economics, Helsinki.

[17] Jabagi, N., Croteau, A.M., Audebrand. L.K., et al. (2019). 'Gig-workers' motivation: Thinking beyond carrots and sticks". Journal of Managerial Psychology, 34(1): 192-213.

[18] Jacobs, J.A. (2016). Gamification in an Online
Course: Promoting student Achievement through Game-Like Elements. Ph.D. Dissertation. University of Cincinnati.

[19] Jain, A. \& Dutta, D. (2018). "Millennials and Gamification: Guerilla Tactics for Making Learning Fun”. South Asian Journal of Human Resources Management, 6(1):1-16.

[20] King, R. (2013). "ROD's 5 Gamification Design Questions: A Simpler, Faster, and Funner Toolkit for Designing Gamified Business Models" [online]. Retrieved from: https://www.slideshare.net/RodKing/rod-gamificat ion-pyramid-templaterodking

[21] Koivisto, J., \& Hamari, J. (2014). "Demographic differences in perceived benefits from gamification". Computers in Human Behavior, 35: $179-188$

[22] Kumar, J. (2013). "Gamification at Work: Designing Engaging Business Software". International Conference of Design, User Experience, and Usability, 528-537.

[23] Kusuma, G. P., Wigati, E. K., Utomo, Y., \& Putera Suryapranata, L. K. (2018). "Analysis of gamification models in education using MDA framework". Procedia Computer Science, 135: 385-392.

[24] Landers, R. N., \& Armstrong, M. B. (2017). "Enhancing instructional outcomes with gamification: An empirical test of the technology-enhanced training effectiveness model". Computers in Human Behavior, 71: 499-507.

[25] Landers, R. N., Bauer, K. N., \& Callan, R. C. (2015). "Gamification of task performance with leaderboards: A goal setting experiment". Computers in Human Behavior, 71: 508-515.

[26] Lee, S. (2007), "Vroom's expectancy theory and the public library customer motivation model", Library Review, 56(9): 788-796.

[27] Liu, M., Huang, Y. and Zhang, D. (2018). "Gamification's impact on manufacturing: Enhancing job motivation, satisfaction and operational performance with smartphone-based gamified job design". Human Factors and Ergonomics in Manufacturing \& Service Industries, 28(1): 38-51.

[28] Locke, E. A., \& Latham, G. P. (1990). A theory of goal setting \& task performance. Englewood Cliffs, N.J: Prentice Hall.

[29] Lopez, C. E., \& Tucker, C. S. (2019). "The effects of player type on performance: A gamification case study". Computers in Human Behavior, 91: 333-345.

[30] Marczewski, A. (2012). Gamification: a simple introduction. (pp. 7-9)

[31] Marczewski, A. (2015). User Types. In Even Ninja Monkeys Like to Play: Gamification, Game Thinking and Motivational Design (1st ed., pp. 65-80).

[32] Matsumoto, T. (2016). "Motivation strategy using 
gamification". Creative Education, 7(10): 1480-1485.

[33] Mitchell, R., Schuster, L. \& Jin, H.S. (2020). "Gamification and the impact of extrinsic motivation on needs satisfaction: Making work fun?". Journal of Business Research, 106: 323-330.

[34] Murawski, L. (2020). "Gamification in human resource management - Status quo and quo vadis". German Journal of Human Resource Management. 35(3): 337-355.

[35] Nacke LE and Deterding S (2017). "The maturing of gamification research". Computers in Human Behavior, 71: 450-454.

[36] Perryer, C., Celestine, N. A., Scott-Ladd, B., \& Leighton, C. (2016). "Enhancing workplace motivation through gamification: Transferrable lessons from pedagogy". International Journal of Management Education, 14(3): 327-335.

[37] Quantic Foundry (2021). "Gamer motivation model". [online]. Retrived from: https:/quanticfoundry.com/wp-content/uploads/20 19/04/Gamer-Motivation-Model-Reference.pdf

[38] Reeves, B., \& Reed, J. L. (2009). Total Engagement: How Games and Virtual Worlds Are Changing the Way People Work and Businesses Compete. Harvard Business Press.

[39] Richter, G., Raban, D.R. \& Rafaeli, S. (2015). "Studying Gamification: The Effect of Rewards and Incentives on Motivation". Gamification in Education and Business. 21-46.

[40] Robson, K., Plangger, K., Kietzmann, J. H., McCarthy, I., \& Pitt, L. (2015). "Is it all a game? understanding the principles of gamification". Business Horizons, 58(4): 411-420.

[41] Ruhi, U. (2015). "Level up your strategy: Towards a descriptive framework for meaningful enterprise gamification". Technology Innovation Management Review, 5(8): 5-16.

[42] Sailer, M., Hense, J., Mandl, H., \& Klevers, M. (2014). "Psychological perspectives on motivation through gamification". Interaction Design and
Architecture(s), 19: 28-37.

[43] Junior, S.S.B., Santos, R. R., Carvalho, J. S., Gabriele de Paula Silva, \& Silva, D. d. (2013). "Possibilities between motivation and productivity: A case study in the upper tietê". Revista Sociedade, Contabilidade e Gestão, 8(3), 090-104.

[44] Skinner, B. F. (1963). "Operant behavior". American Psychologist, 18(8), 503-515.

[45] Suh, A., \& Wagner, C. (2017). "How gamification of an enterprise collaboration system increases knowledge contribution: An affordance approach". Journal of Knowledge Management, 21(2), 416-431.

[46] Suh, A., Suh, A., Cheung, C. M. K., Ahuja, M., Wagner, C., \& Wagner, C. (2017). "Gamification in the workplace: The central role of the aesthetic experience". Journal of Management Information Systems, 34(1), 268-305.

[47] Vinichenko, M. V., Melnichuk, A. V., Kirillov, A. V., Makushkin, S. A., \& Melnichuk, Y. A. (2016). "Modern views on the gamification of business". Journal of Internet Banking and Commerce, 21(S3): 1.

[48] Werbach, K., \& Hunter, D. (2012). For the win: How game thinking can revolutionize your business. Philadelphia, PA: Wharton Digital Press.

[49] Werbach, K. (2014). "(Re)Defining Gamification: A Process Approach". International Conference on Persuasive Technology, 266-272.

[50] Xi, N., \& Hamari, J. (2019). "Does gamification satisfy needs? A study on the relationship between gamification features and intrinsic need satisfaction". International Journal of Information Management, 46: 210-221.

[51] Yu-kai Chou (2019). Yu-kai Chou: Gamification \& Behavioral Design. Retrieved from: https://yukaichou.com/gamification-examples/octa lysis-complete-gamification-framework/.

[52] Zichermann, G., \& Cunningham, C. (2011). Gamification by Design - Implementing Game Mechanics in Web and Mobile Apps. Sebastopol, CA: O’Reilly Media. 


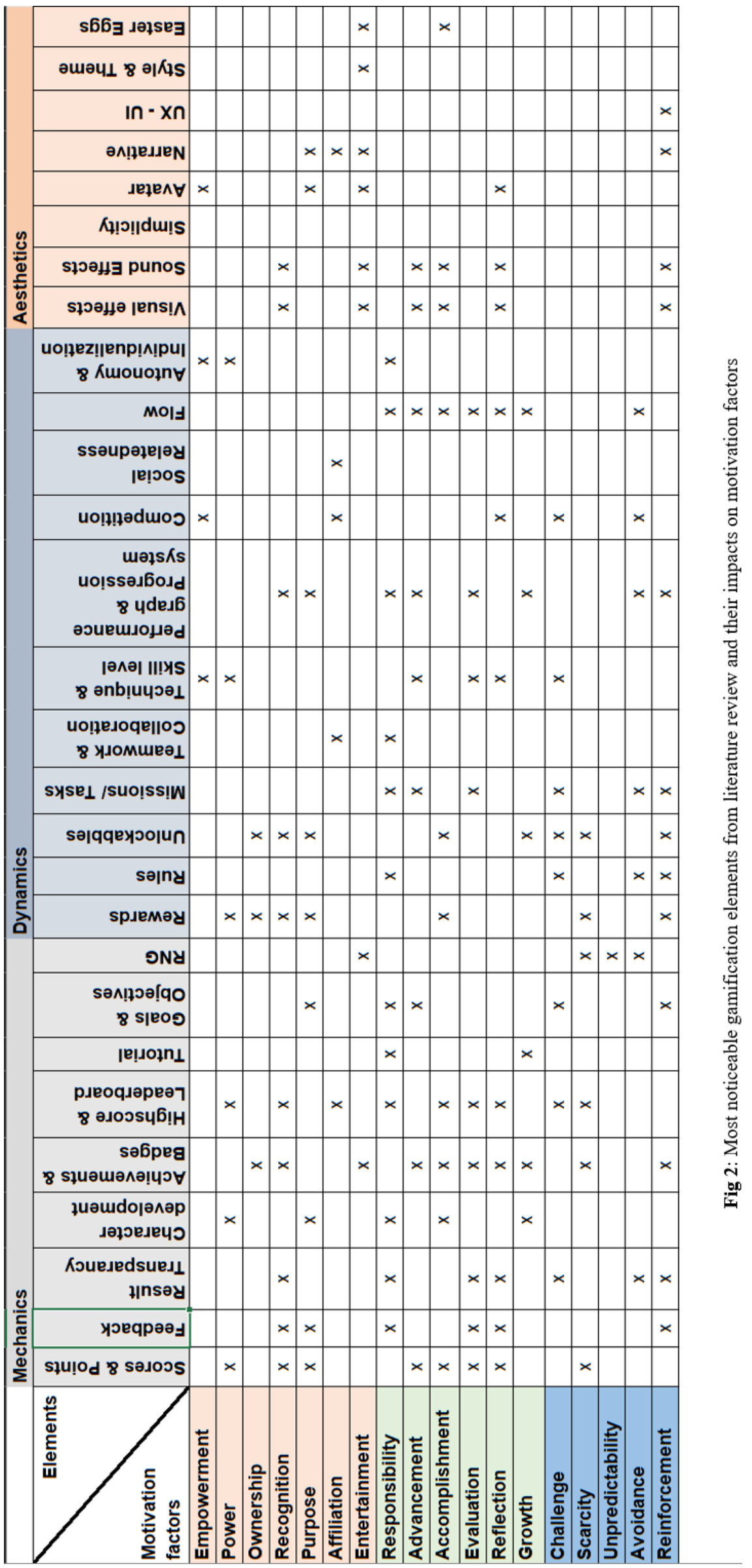

